\title{
PERSPECTIVE: PREFERENTIAL FLOW IN RIPARIAN BUFFERS: CURRENT RESEARCH AND FUTURE NEEDS
}

\author{
Derek M. Heeren ${ }^{1, *}$, Lucie Guertault ${ }^{2}$, Kyle Mankin ${ }^{3}$ \\ ${ }^{1}$ Department of Biological Systems Engineering, University of Nebraska-Lincoln, Lincoln, Nebraska, USA. \\ ${ }^{2}$ Department of Biological and Agricultural Engineering, North Carolina State University, Raleigh, North Carolina, USA. \\ ${ }^{3}$ USDA-ARS Water Management and Systems Research Unit, Fort Collins, Colorado, USA. \\ *Correspondence: derek.heeren@unl.edu.
}

\section{HighLights}

- Preferential flow (PF) can critically reduce riparian buffer contaminant removal efficiency.

- This collection presents research on PF measurement, visualization, modeling, and contaminant transport impacts.

- Future needs include tools to identify landscape-scale PF areas and conservation practices.

- Future models for research and practice should account for PF in riparian buffers.

\begin{abstract}
Preferential flow in riparian buffers can substantially compromise their effectiveness in reducing contaminants from overland runoff. The objective of this article is to introduce a collection of five articles on current research into subsurface preferential flow measurement, visualization, modeling, and impacts on contaminant fate and transport at scales ranging from the subsurface pore scale to the plot scale to the watershed scale. This collection presents selected works from a broader invited session on "Preferential flow and piping in riparian buffers" at the 2020 ASABE Annual International Meeting. Major findings include: new methodologies, such as light transmission and geophysics, to characterize subsurface preferential flow; an infiltration partitioning approach to quantify preferential flow from field experiments; a kinematic dispersive wave model to effectively simulate subsurface preferential flow; and the significant impact of surface concentrated flow pathways on pesticide fate and transport both upstream and within a riparian buffer. Future work is needed to develop methods and tools to identify PF areas and management solutions within a landscape, and to update both research and design models to better quantify and account for PF processes.
\end{abstract}

Keywords. Best management practice, Buffer strip, Agricultural conservation practice, Filter strip, Macropore, Nonpointsource pollution.

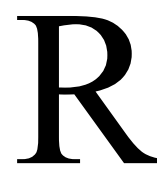

iparian buffers can be used as filters to remove contaminants from overland runoff and subsurface flow before entering a surface water body. A recent review (Douglas-Mankin et al., 2021) found edge-of-field buffers to be most effective at removing sediment ( $78 \%$ average) along with contaminants attached to the sediment, such as phosphate (63\% average). Highly soluble contaminants, such as nitrate-N, tend to stay in solution until the runoff reaches the water body; however, depending on the geography and soil properties, riparian buffers may increase infiltration and remove nitrate-N through subsurface denitrification. Total nitrogen removal averaged $57 \%$ among 71 treatments in the literature (Douglas-Mankin et al., 2021), although removal ranged from near zero to

Submitted for review on 28 June 2021 as manuscript number NRES 14732; approved for publication as a Perspective Article and as part of the Preferential Flow and Piping in Riparian Buffers Collection by the Natural Resources \& Environmental Systems Community of ASABE on 23 September 2021.

Mention of company or trade names is for description only and does not imply endorsement by the USDA. The USDA is an equal opportunity provider and employer.
$98 \%$, and removal was lower and variability higher for nitrate-N. The effectiveness of riparian buffers for removing pesticides depends on the solubility of the pesticide and the infiltration characteristics of the buffer. Douglas-Mankin et al. (2021) found atrazine removal averaged $65 \%$ among 59 treatments in the literature, and alachlor removal averaged $72 \%$ among 67 treatments, but again, each had ranges from near zero removal to $100 \%$. Buffers in Nebraska are primarily used for sediment removal; however, in one watershed, conservation buffers reduced atrazine transport to the stream by $31 \%$ (Franti et al., 2004). The source of some of this variability in contaminant removal among buffers may be preferential flow (PF), that is, localized zones of rapid water flow and contaminant transport. Here we define PF to include occurrences both on the soil surface (e.g., concentrated flow pathways) and in the subsurface (e.g., macropores).

Originally, buffers were conceived as two-dimensional (i.e., a vertical, two-dimensional profile), with the original name of "buffer strip" implying a constant buffer width. However, overland flow through agricultural fields and buffers is a three-dimensional process, with surface $\mathrm{PF}$ 


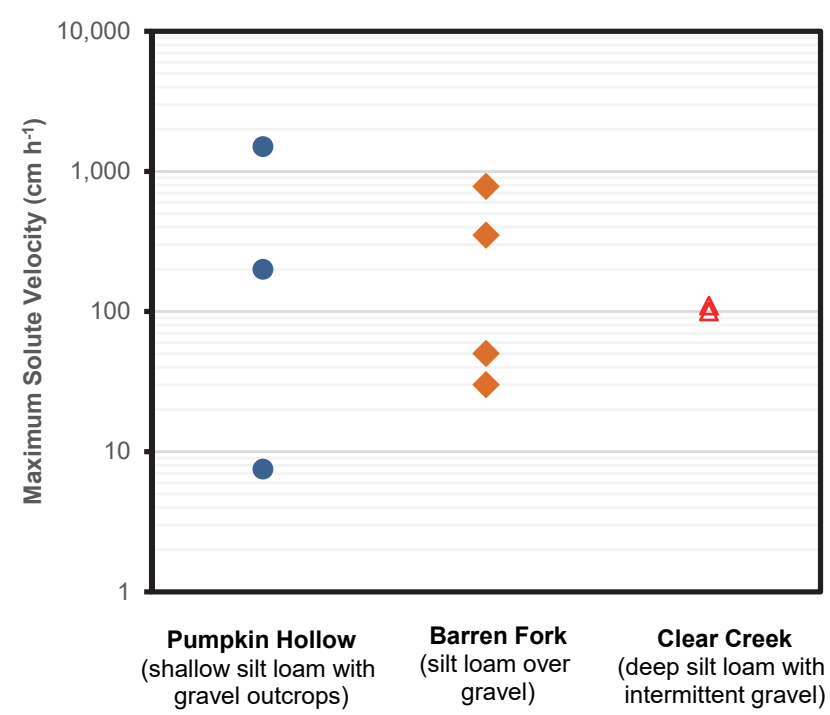

Figure 1. Transport of Rhodamine WT dye from the soil surface to the water table during plot-scale saturated infiltration experiments in the Ozark ecoregion. Each point is the maximum measured solute velocity for one infiltration plot (adapted from Heeren et al., 2017).

significantly limiting the effectiveness of riparian buffers (e.g., Dosskey et al., 2002). In one case, flow convergence in a contributing field was found to have a greater impact on buffer effectiveness than flow convergence within the buffer (Helmers et al., 2005).

Regarding infiltration and $\mathrm{PF}$ in the vadose zone, macropores have been the subject of early and ongoing research (Beven and Germann, 1982). Riparian buffers are uniquely susceptible to PF through macropores due to geomorphic depositions, abundant roots and other biological activity, frequent drying/wetting cycles, and landscape position (runon increases frequency of ponding and macropore activation). For example, field infiltration experiments in riparian floodplains in the Ozark ecoregion demonstrated that even phosphate-P can leach through the vadose zone rapidly, with transport being highly preferential (Heeren et al., 2017). Transport rates of a Rhodamine WT dye ranged over orders of magnitude (figs. 1 and 2), with the highest velocities $\left(10^{3}\right.$ $\mathrm{cm} \mathrm{h}^{-1}$ ) occurring at sites with a smaller layer of fine-textured soil and, implicitly, greater macropore connectivity from the soil surface to the water table. In some cases, the maximum solute velocity was up to an order of magnitude higher than the expected mean pore water velocity. While riparian buffers and other conservation practices are primarily aimed at reducing surface runoff contributions of colloids, $\mathrm{N}$, and $\mathrm{P}$, their effectiveness may be significantly reduced by the presence of subsurface PF.

\section{INVITED SESSION}

An invited session on "Preferential flow and piping in riparian buffers" was held at the 2020 ASABE Annual International Meeting. The session was organized to address topics such as mechanisms of PF in the vadose zone, PF in surface runoff, field and/or laboratory experiments, modeling $\mathrm{PF}$, impacts of $\mathrm{PF}$ on flow and transport, and impacts of PF

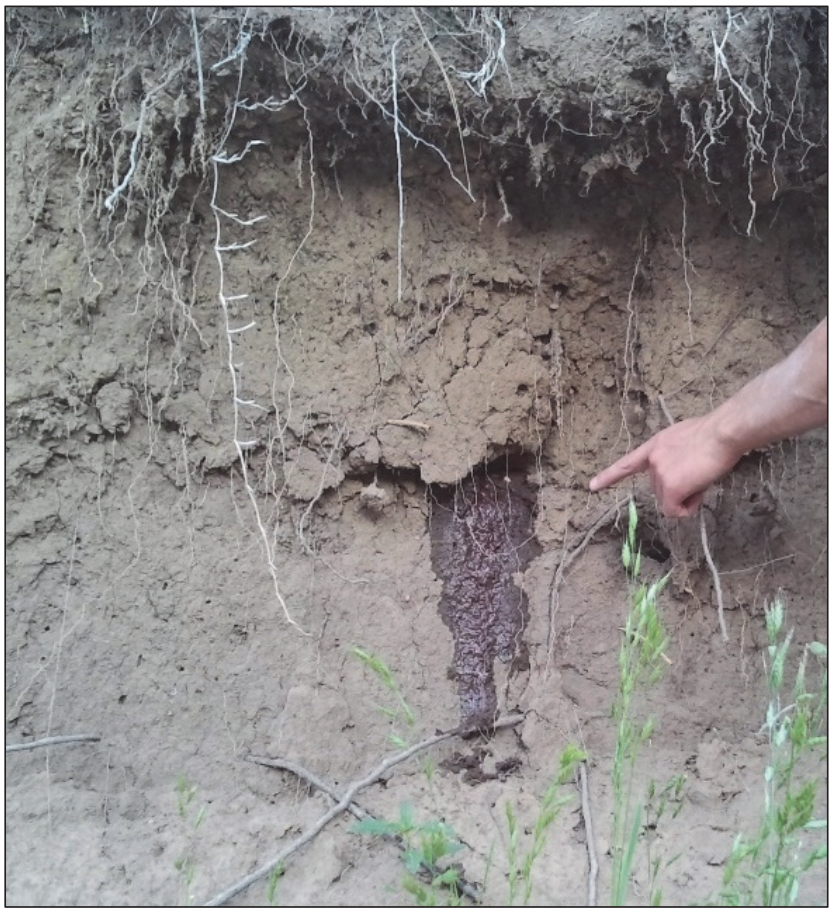

Figure 2. Macropores exposed on a streambank at the Barren Fork Creek site, with water and dye reaching the streambank during an infiltration experiment (photo credit Garey Fox).

on surface water quality. Seven presentations on current research included speakers from North Carolina State University, Oklahoma State University, Pennsylvania State University, University of Florida, USDA Agricultural Research Service, and Virginia Tech. The session was sponsored by ASABE committees including NRES-21 Hydrology, NRES253 Riparian Zones, Floodplains, and Wetlands, and NRES28 Ecological Engineering.

Several presentations addressed the topic of PF at the plot scale. Research on infiltration experiments included riparian field sites in North Carolina (Dr. Guertault) and Kenya (Mr. Orozco-López). Geophysics was explored as a method to identify macropore fingering (Dr. Halihan). Other presentations focused on PF at the landscape scale. Research on surface concentrated flow pathways through riparian buffers included sediment and nutrient transport (Dr. Veith) and pesticide transport (Dr. Preisendanz). Dr. Veith noted that 27 of 52 analyzed buffers were undermined by concentrated flow pathways. Presentations on soil pipes included their role in connecting upper hillslopes with streams (Dr. Wilson) and their role in bank storage (Mr. Lotts). Dr. Wilson demonstrated that the hydrologic connectivity of soil pipes is a threshold-driven process, with pipeflow dependent on storm event dynamics and antecedent soil moisture conditions. Results from Mr. Lotts' modeling indicated that soil pipes may play a role in expanding hyporheic zone denitrification, possibly reducing stream nitrate- $\mathrm{N}$ concentrations at the reach scale. A key take-home message from the discussion at the conclusion of the session was the need to develop tools and methods to be able to identify areas of PF within a landscape and to develop best management practices for specific problem areas instead of entire riparian areas. 


\section{SPecial Collection Contributions}

This Special Collection includes five articles (table 1) from the speakers at the invited session. Four articles focus on subsurface PF and address the development and implementation of approaches to visualize, characterize, and/or quantify subsurface $\mathrm{PF}$ at scales ranging from the pore scale to the plot scale and the evaluation of modeling approaches to predict soil water contents and infiltration rates in riparian buffers. The fifth article is a reconnaissance study that investigates the role of surface concentrated flow pathways on contaminant fate and transport in various agricultural systems and riparian buffers.

Measuring PF can be done using a number of methods, including light transmission, temporal electrical resistivity imagery (TERI), partitioning infiltration, and kinematic dispersive wave modeling. Muñoz-Carpena and Orozco-Lopez (2021) propose a refined mathematical model to quantify soil water content from light intensity attenuation and describe a testing methodology for collecting baseline data at the residual and saturated water contents for calibrating model parameters such as the representative pore radius and the number of pores crossed by the light signal. The light transmission method is a non-contact, high-resolution approach to observe soil moisture in laboratory soil samples at the pore scale. This method provides opportunities to observe flow process at high spatial and temporal resolutions and could help improve the understanding of complex processes such as the diffusion of water from a PF pathway into the surrounding matrix; however, mathematical models to quantify soil water content from light intensity attenuation still lack consistency and reliability. Accurate estimates of soil water flow rates were obtained from these high-resolution soil water content measurements, with larger errors observed closed to residual and saturated water content conditions. Given that their experiment was on fine sand requiring high exposure to light, the authors estimated that the light transmission method would not be applicable for fine sediment.

While light transmission focuses on micro-scale measurement, observations at practical scales are critical to better understand the factors controlling the initiation and rates of preferential transport in riparian buffers. Halihan et al. (2021) evaluated the applicability of TERI to detect wetting patterns associated with macropore flow in a riparian buffer. TERI consists in measuring temporal changes in the electrical resistivity of a cross-section of the subsurface using a row of electrodes. A temporal increase of electrical resistivity typically indicates an increase in soil water contents and can be used to monitor soil water movement over time. The authors conducted controlled experiments to determine whether TERI could detect a single macropore and a series of three macropores, which would eventually allow the identification and characterization of macropore structures in soil, often needed to inform mathematical models for the simulation of subsurface PF. TERI was obtained in the vicinity of artificial macropores created at two field sites of contrasting soil types (located in Oklahoma and North Carolina) and under both unsaturated and saturated conditions. A background measurement corresponding to initial, relatively steady conditions was obtained to estimate the level of noise associated with the setup and site conditions. The electrical resistivity was then monitored over time to capture changes in wetting patterns. These experiments showed that TERI with dense electrode spacing $(0.4 \mathrm{~m})$ can detect the wetting front around individual artificial macropores under both saturated and unsaturated conditions, thereby qualitatively indicating the presence of PF pathways. However, the technique cannot be used to characterize macropore properties, such as structure and size.

Quantitative data are especially critical to test mathematical formulations to model PF that could be incorporated into hydrologic models used for buffer design and evaluation. Guertault et al. (2021) proposed an approach to partition infiltration in a riparian buffer during runoff events between matrix flow and PF using a water budget combining in situ measurements and numerical simulations. The approach was developed and tested in a riparian buffer with sandy soil located in North Carolina. The first set of experiments consisted of sprinkler tests with low surface input rates and unsaturated soil conditions, for which matrix flow was assumed to be the predominant process. Point-scale measurements of soil water content were obtained across the buffer at a depth of $10 \mathrm{~cm}$. Inverse modeling was used to determine soil hydraulic properties representative of the soil matrix. In a second set of experiments, known surface inflow rates were introduced into the buffer, and surface flow rates were measured at the outlet. For these tests, soil matrix infiltration was estimated using numerical simulation. A water budget was then used to obtain a first-order approximation of preferential infiltration rates from the difference between surface inflow and the surface outflow and matrix infiltration rates.

Table 1. Summary of articles included in the 2021 ASABE Special Collection on preferential flow (PF) in riparian buffers.

\begin{tabular}{|c|c|c|c|}
\hline Authors & Title & Topic & DOI \\
\hline $\begin{array}{l}\text { Guertault, L., Fox, G., } \\
\text { Halihan, T., \& } \\
\text { Muñoz-Carpena, R. }\end{array}$ & $\begin{array}{l}\text { Quantifying the importance of preferential flow } \\
\text { in a riparian buffer }\end{array}$ & $\begin{array}{c}\text { Plot-scale } \\
\text { subsurface PF }\end{array}$ & https://doi.org/10.13031/trans.14286 \\
\hline $\begin{array}{l}\text { Halihan, T., Hager, J., } \\
\text { Guertault, L., \& Fox, G. }\end{array}$ & $\begin{array}{l}\text { Detecting macropore fingering using temporal } \\
\text { electrical resistivity imaging }\end{array}$ & $\begin{array}{c}\text { Meso-scale } \\
\text { subsurface PF }\end{array}$ & https://doi.org/10.13031/aea.14294 \\
\hline $\begin{array}{l}\text { Muñoz-Carpena, R., } \\
\text { \& Orozco-Lopez, E. }\end{array}$ & $\begin{array}{c}\text { Comparative non-Darcian modeling of subsurface } \\
\text { preferential flow: Experimental observations } \\
\text { in a riparian buffer }\end{array}$ & $\begin{array}{c}\text { Plot-scale } \\
\text { subsurface PF }\end{array}$ & https://doi.org/10.13031/trans.14559 \\
\hline $\begin{array}{l}\text { Muñoz-Carpena, R., } \\
\text { Orozco-Lopez, E., } \\
\text { Gao, B., \& Fox, G. }\end{array}$ & $\begin{array}{l}\text { High-resolution pore-scale water content measurement } \\
\text { in a translucent soil profile from light transmission }\end{array}$ & $\begin{array}{c}\text { Micro-scale } \\
\text { subsurface PF }\end{array}$ & https://doi.org/10.13031/trans.14292 \\
\hline $\begin{array}{l}\text { Preisendanz, H., Chandler, J., } \\
\text { Veith, T., Elkin, K., Elliott, H., } \\
\text { Watson, J., \& Kleinman, P. }\end{array}$ & $\begin{array}{c}\text { Role of concentrated flow pathways on the movement } \\
\text { of pesticides through agricultural fields and } \\
\text { riparian buffer zones }\end{array}$ & $\begin{array}{l}\text { Surface PF and } \\
\text { contaminant fate } \\
\text { and transport }\end{array}$ & https://doi.org/10.13031/trans.14221 \\
\hline
\end{tabular}


This study demonstrated that PF contributed significantly to infiltration in the riparian buffer and that its contribution depended on the specific hydrologic conditions, such as the initial soil water content and inflow rates relative to the total infiltration capacity.

Muñoz-Carpena et al. (2021) evaluated two mathematical models proposed for the simulation of non-sequential water movement due to PF: a kinematic dispersive wave model modified to incorporate $\mathrm{PF}$, and a source responsive model using experimental data collected in a riparian buffer with clayey soils located in Kenya. They measured soil water contents across the buffer under single-rate sprinkler experiments in three trenches with either wet or dry initial conditions using dielectric sensors positioned in a $5 \times 4$ grid pattern, $80 \mathrm{~cm}$ tall and $45 \mathrm{~cm}$ wide. Their experimental setup captured non-sequential wetting patterns typical of PF, especially for the dry initial condition scenario. The models performed well in simulating observed water content during the single-rate experiments. The source responsive model required prior knowledge of key model variables that were also found to depend on initial conditions and had to be recalibrated, thereby limiting its predictive capabilities. The modified kinematic dispersive wave model had more robust model parameters that could allow the simulation of PF for a range of initial and boundary conditions once calibrated.

Preisendanz et al. (2021) examined the interconnected effects of land use, concentrated flow pathways, and pesticide physico-chemical properties on pesticide fate and transport in an agricultural watershed with loamy soils. Soil concentrations of atrazine, metolachlor, and imidacloprid were measured from samples collected along concentrated flow pathways and overland flow pathways at nine sites with varying land uses (row crop field, pasture, and riparian buffer). Pesticide concentrations in riparian buffers were lower than the concentrations measured in upland fields, and concentrations inside the buffer were typically higher along concentrated flow pathways, demonstrating the bypass effect caused by concentrated flow pathways that can limit the effectiveness of buffers. The authors also highlighted the role of upland conditions, the interactions between the pesticide application methods (sprayed onto the surface or introduced into the soil as seed coating), and the presence of concentrated flow pathways either at the surface or subsurface in determining pesticide export from upland fields to riparian buffers.

\section{FUtURE NEEDS}

Based on this Special Collection of articles, as well as the invited session, we identified key future needs related to preferential flow $(\mathrm{PF})$ in riparian buffers. For large-scale PF (including surface runoff and soil piping), there is a need to develop methods and tools to identify PF areas within a landscape, and to create site-specific best management practices that can be used to address specific PF problem areas. For small-scale PF (macropores, biopores, etc.), there is a need to develop methods and tools to better quantify PF in the lab and field, and to update models to account for PF. Model enhancements are needed for both researchers and practitioners.

\section{CONCLUSIONS}

The research presented in this Special Collection advances the science of preferential flow (PF) processes in riparian buffers. The collection presented research on using light transmission for measuring soil water contents and flow rates in buffers, on using temporal electrical resistivity imagery to indicate the presence of PF pathways, on partitioning buffer infiltration between matrix flow and PF by combining in situ measurements and numerical simulations, on testing two modeling approaches for simulating non-sequential water movement due to PF, and on the effect of PF on limiting buffer effectiveness for pesticide removal in an agricultural watershed. Areas for future research are presented, including an urgent need for better models and tools that include the effects of PF processes, both for research and riparian buffer design.

\section{ACKNOWLEDGEMENTS}

The authors would like to acknowledge financial support from USDA National Institute of Food and Agriculture (NIFA) Project No. 2016-67019-26855. We would also like to acknowledge Dr. Tom Franti, Dr. Dean Eisenhauer, and Mr. Alan Boldt for sharing their insights during the development of the manuscript.

\section{REFERENCES}

Beven, K., \& Germann, P. F. (1982). Macropores and water flow in soils. Water Resour. Res., 18(5), 1311-1325. https://doi.org/10.1029/WR018i005p01311

Dosskey, M. G., Helmers, M. J., Eisenhauer, D. E., Franti, T. G., \& Hoagland, K. D. (2002). Assessment of concentrated flow through riparian buffers. J. Soil Water Cons., 57(6), 336-343.

Douglas-Mankin, K. R., Helmers, M. J., \& Harmel, R. D. (2021). Review of filter strip performance and function for improving water quality from agricultural lands. Trans. ASABE, 64(2), 659674. https://doi.org/10.13031/trans.14169

Franti, T. G., Eisenhauer, D. E., McCullough, M. C., Stahr, L. M., Dosskey, M. G., Snow, D. D., ... Boldt, A. L. (2004). Watershed-scale impacts of buffers and upland conservation practices on agrochemical delivery to streams. ASAE Paper No. 701P0904. St. Joseph, MI: ASAE.

Guertault, L., Fox, G. A., Halihan, T., \& Muñoz-Carpena, R. (2021). Quantifying the importance of preferential flow in a riparian buffer. Trans. ASABE, 64(3), 937-947. https://doi.org/10.13031/trans.14286

Halihan, T., Hager, J. P., Guertault, L., \& Fox, G. A. (2021). Detecting macropore fingering using temporal electrical resistivity imaging. Appl. Eng. Agric., 37, in press. https://doi.org/10.13031/aea.14294

Heeren, D. M., Fox, G. A., Penn, C. J., Halihan, T., Storm, D. E., \& Haggard, B. E. (2017). Impact of macropores and gravel outcrops on phosphorus leaching at the plot scale in silt loam soils. Trans. ASABE, 60(3), 823-835. https://doi.org/10.13031/trans.12015

Helmers, M. J., Eisenhauer, D. E., Franti, T. G., \& Dosskey, M. G. (2005). Modeling sediment trapping in a vegetative filter 
accounting for converging overland flow. Trans. ASAE, 48(2), 541-555. https://doi.org/10.13031/2013.18328

Muñoz-Carpena, R., \& Orozco-Lopez, E. (2021). Comparative nonDarcian modeling of subsurface preferential flow experimental observations in a riparian buffer. Trans. ASABE, in press. https://doi.org/10.13031/trans.14559

Muñoz-Carpena, R., Orozco-Lopez, E., Gao, B., \& Fox, G. (2021). High-resolution pore-scale water content measurement in a translucent soil profile from light transmission. Trans. $A S A B E$, 64(3), 949-962. https://doi.org/10.13031/trans.14292

Preisendanz, H. E., Chandler, J. W., Veith, T. L., Elkin, K. R., Elliott, H. A., Watson, J. E., \& Kleinman, P. J. (2021). Role of concentrated flow pathways on the movement of pesticides through agricultural fields and riparian buffer zones. Trans. $A S A B E$, 64(3), 975-986. https://doi.org/10.13031/trans.14221 